\title{
Survival and Pulmonary Injury After Neonatal Sepsis: PD1/PDL1's Contributions to Mouse and Human Immunopathology
}

\section{Eleanor A. Fallon ${ }^{1}$, Chun-Shiang Chung ${ }^{1}$, Daithi S. Heffernan ${ }^{1,2}$, Yaping Chen ${ }^{1}$, Monique E. De Paepe ${ }^{3}$ and Alfred Ayala ${ }^{1 *}$}

${ }^{1}$ Division of Surgical Research, Department of Surgery, Alpert Medical School of Brown University, Rhode Island Hospital, Providence, RI, United States, ${ }^{2}$ Department of Surgery, Providence Veterans Affairs Medical Center, Providence, Rl, United States, ${ }^{3}$ Department of Pathology, Women \& Infants Hospital and Alpert Medical School of Brown University, Providence, RI, United States

Morbidity and mortality associated with neonatal sepsis remains a healthcare crisis. PD1-/- neonatal mice endured experimental sepsis, in the form of cecal slurry (CS), and showed improved rates of survival compared to wildtype (WT) counterparts. End-organ injury, particularly of the lung, contributes to the devastation set forth by neonatal sepsis. PDL1 $1^{-/-}$neonatal mice, in contrast to $\mathrm{PD} 1^{-/}$neonatal mice did not have a significant improvement in survival after CS. Because of this, we focused subsequent studies on the impact of PD1 gene deficiency on lung injury. Here, we observed that at $24 \mathrm{~h}$ post-CS (but not at 4 or $12 \mathrm{~h}$ ) there was a marked increase in pulmonary edema (PE), neutrophil influx, myeloperoxidase (MPO) levels, and cytokine expression sham (Sh) WT mice. Regarding pulmonary endothelial cell (EC) adhesion molecule expression, we observed that Zona occludens-1 (ZO-1) within the cell shifted from a membranous location to a peri-nuclear location after CS in WT murine cultured ECs at 24hrs, but remained membranous among PD1 ${ }^{-/-}$lungs. To expand the scope of this inquiry, we investigated human neonatal lung tissue. We observed that the lungs of human newborns exposed to intrauterine infection had significantly higher numbers of PD1 ${ }^{+}$cells compared to specimens who died from non-infectious causes. Together, these data suggest that PD1/PDL1, a pathway typically thought to govern adaptive immune processes in adult animals, can modulate the largely innate neonatal pulmonary immune response to experimental septic insult. The potential future significance of this area of study includes that PD1/PDL1 checkpoint proteins may be viable therapeutic targets in the septic neonate.

Keywords: programmed cell death receptor, sepsis, lung injury, immunopathology, innate immunity, neonatal, survival, endothelial cell culture

\section{INTRODUCTION}

Sepsis remains a devastating illness with high morbidity and mortality despite diagnostic and supportive therapeutic advances over the past several decades $(1,2)$. The costs of sepsis on the healthcare system remain economically burdensome (3). Among surgical patients, an intra-abdominal source of the sepsis is a predominant driver of this mortality. These effects are most 
profoundly noted in the extremes of age-namely the geriatric and neonatal cohorts $(4,5)$. For the neonatal cohort specifically, mortality has remained relatively unchanged despite significant advances in neonatal critical care $(6,7)$. Compared to the adult cohort, there is a relative paucity of data regarding the neonatal response to an intra-abdominal septic challenge, let alone an agespecific definition of sepsis criteria (8). The detrimental effects of neonatal sepsis are thought to arise from an inadequate response of the immature immune system (9).

Sepsis induces an overwhelming cellular and cytokine cascade that often disrupts the steady-state, or balance, of the immune system (10). When this dysfunction occurs, the result often includes end-organ damage (11). Not only is remote septic organ failure attributed to the bacterial burden of the septic source itself, it is also attributed, perhaps more predominantly so, to multi-factorial immune-cell disharmony (12). Impaired barrier function follows, and circulating neutrophils influx into and habitate within those affected remote organ systems (13).

As an example of this septic organ dysfunction, indirect acute lung injury has been shown to correlate with direct insult to pulmonary endothelium (14). The damage to the microvasculature of the lungs is attributed to this interaction between the endothelial cells and infiltrating neutrophils, and the cell injury/death that follows (15). This indirect acute lung injury contributes to morbidity and mortality in both adult patients and in the murine double-hit model of sepsis and hemorrhage $(16,17)$.

Several models have been described and tested in an attempt to replicate the septic picture found in adults. Cecal Ligation and Puncture (CLP) alone and in combination with hemorrhage for a double-hit scenario have been used predominantly in the Ayala lab (18). The intention of CLP alone is to mimic a clinical picture of a polymicrobial intra-abdominal sepsis, such as perforated diverticulitis (19). The murine models used to mimic adult sepsis are not seamlessly translated to the neonatal model, however.

Although the causes of intra-abdominal sepsis in children are numerous, there are a relatively limited number of etiologies in the newborn population (20). The numerous contributing factors have been distilled down to four pillars: (1) hypoxia and ischemia, (2) bacteria, (3) hypothermia, and (4) formula feeding (21). In this respect, Cecal Slurry (CS) is the purposefully designed reductionist approach to intra-abdominal sepsis. It can be applied across most forms of abdominal sepsis pathologies because it focuses primarily on the pure aspect of the polymicrobial/bacterial burden in the peritoneum and the septic

Abbreviations: ACA, Acute Chorioamnionitis; AFIS, Amniotic Fluid Infection Syndrome; ANOVA, Analysis of Variance; BPD, Bronchopulmonary Dysplasia; CD, Cluster of Differentiation; CHF, Congestive Heart Failure; CLP, Cecal Ligation and Puncture; CS, Cecal Slurry; DiDi, Dichorionic Diamniotic; GA, Gestational Age; GBS, Group B Strep; HMD, Hyaline Membrane Disease; HPF, High Power Field; IF, Immunofluorescence; IMN, Ischemic Myocardial Necrosis; IUGR, Intrauterine Growth Retardation; IVH, Intraventricular Hemorrhage; NEC, Necrotizing Enterocolitis; PA, Placental Abruption; PD1, Program Cell Death Receptor-1; PDL1, Program Cell Death Receptor-1 ligand; PH, Pulmonary Hemorrhage; PIE, Pulmonary Interstitial Emphysema; PNA, Pneumonia; PROM, Preterm Premature Rupture of Membranes; PTL, Premature Labor; PVFD, Perivillous Fibrin Deposition; RDS, Respiratory Distress Syndrome; Sh, Sham; TTTS, Twin to Twin Transfusion Syndrome; WT, Wild Type. sequelae (22). It was first applied to the neonatal murine model by the Wynn/Moldawer labs and has gained traction as a validated model for studying the immunology of neonatal sepsis (23).

There is an almost overwhelming volume of protein contributors to the inflammatory cascade in sepsis. It is recognized that several key regulators of the immune system, often small cell-surface receptors, exist. Programmed cell death receptor-1 (PD1) has arisen as such a key component in both human and animal models. It is a checkpoint protein first discovered by Ishida et al. at Kyoto University, and is known to be involved in both pro- \& anti-inflammatory cascades $(24,25)$. Clinically, human serum samples had increased PD1 expression in adult septic shock (26). Conversely, adult patients who went on to survive Acute Lung Injury exhibited lower levels of PD1 (17).

We have previously established that, among adult mice, PD1 or PDl ligand 1 (PDL1) gene deletion confers a survival advantage following sepsis (27). More recently, we have demonstrated the improved survival effect of PD1 gene deletion on neonatal pups following septic challenge-the neonatal population being a distinct cohort from an immunological perspective, given their under-developed adaptive immune system (28). This led us to the question: what is contributing to the improved survival witnessed in PD1 deficiency among murine neonates after sepsis? On gross necropsy of these mice, the lungs are markedly more edematous and hemorrhagic in the septic cohorts among wildtypes. This injury was less pronounced among the PD1 knock out mice.

Based on these background data, we hypothesize that PD1 plays an integral role in the immune-mediated lung damage induced by CS, and modulation of this checkpoint protein should improve survival after septic challenge. We suggest that improved sepsis survival seen in $\mathrm{PD}^{-/-}$pups is driven by endorgan effects, specifically sepsis mediated changes in the lung. Further, building on the understanding that innate immunity is emphasized at the neonatal developmental stage, we contend that PD1 induces neutrophilic burden in the lung, which regulates expression of its ligand PDL1 and contributes to compromised parenchymal integrity.

\section{MATERIALS AND METHODS}

\section{Animals}

Wild type (WT) C57BL/6J mouse pups were bred from adult mice (Jackson Laboratory, Bar Harbor, ME). Wild type mice deficient in PD1 (PD1 ${ }^{-/}$) were used to breed the knockout pups (kindly provided by Tasuku Honjo, Kyoto University, Kyoto, Japan, through Megan Sykes at Massachusetts General Hospital, Boston, MA). Mice were bred at the Rhode Island Hospital (RIH) rodent facility and received standard care and diet ad libitum. Neonatal pups between 5 and 7 days old were utilized for each experiment in accordance with the Institutional Animal Care and Use Committee of Rhode Island Hospital (AWC\# 506418), the Animal Welfare Act, and National Institutes of Health guidelines for animal care and use.

\section{Animal Model of Sepsis}

We employed the cecal slurry (CS) model for murine neonatal sepsis based on the previously described model from the 
Moldawer lab, and adapted for utilization in our experiments $(23,28)$. In brief, an adult male WT mouse served as the donor of cecal contents for each experiment. Contents were combined in a weight-based manner with $5 \%$ dextrose to solution in order to create the cecal slurry of $80 \mathrm{mg} / \mathrm{mL}$ concentration. Pups received an intra-peritoneal injection of this CS $(1.3 \mathrm{mg} / \mathrm{g}$ body weight to produce $\mathrm{LD}_{70}$ ) or a Sham (Sh) injection of equivalently weightbased crystalloid solution. For further details, please refer to Young et al. (28).

\section{Survival Study}

A 7-day survival study was undertaken to compare mortality as the primary outcome. WT, $\mathrm{PD}^{-/-}$, and $\mathrm{PDL}^{-/-}$pups underwent either Sh or CS injection, followed by a period of observation. Pups were examined approximately every $6 \mathrm{~h}$ over the initial 48-h period, followed by observation approximately every $12 \mathrm{~h}$ for the subsequent 5 days.

\section{Wet: Dry Weights}

Twenty-four hours after Sh or CS, whole lungs were harvested and weighed. This immediate weight was documented as the wet weight. Serial dry weights were measured starting at $24 \mathrm{~h}$ following harvest and were concluded once a difference between serial weights was no longer detected. The ratio of the Wet:Dry weights was then calculated.

\section{Bacterial Culture}

As per the animal model, pups were injected with either CS or Sh crystalloid, and observed for $24 \mathrm{~h}$. Following this period, lung tissue was homogenized and $100-\mu l$ samples were plated onto sheep's blood agar plates. After $24 \mathrm{~h}$ of incubation at $37.5^{\circ} \mathrm{C}$, the plates were assessed and colony forming units (CFUs) were quantified.

\section{Histology}

Lungs were harvested at $24 \mathrm{~h}$ following injection (either Sh injection or CS) and maintained in formalin for sectioning. The RIH Core Research Laboratory processed these samples into paraffin wax blocks and sectioned them for staining. Sectioned samples were stained with hematoxylin and eosin (H\&E) to allow for gross visual comparison of pulmonary architecture.

Additional samples were stained with naphthol esterase to identify granulocytic cells as a marker for neutrophils. Neutrophil presence was assessed by determining the number of neutrophils present per 5 high power fields on these immunohistochemistry slides. All samples were analyzed by an attending pathologist (by MD) blinded to the sample identity.

\section{Flow Cytometry}

The lungs were digested to single cell suspensions using the Miltenyi Biotec lung dissociation kit as per manufacturer's instructions. Cells were counted to establish the absolute numbers of cells within each lung sample from which subpopulation numbers could be calculated. Cell subpopulations were identified by forward and side scatter profile and subsequently gated using monoclonal antibodies (listed below) along with appropriate isotype controls according to both manufacturer's recommendation and our prior publications (27).
The fluorochrome-conjugated monoclonal antibodies used here were: PE-labeled anti-CD3e (clone 145-2C11; T-cells), and APC-labeled anti-Gr1 (clone RB6-8C5; Neutrophils) from eBioscience. In additional experiments, neutrophils were also double stained as being $\mathrm{Ly}_{6} \mathrm{G}^{+} \mathrm{CD}_{11 \mathrm{~b}}{ }^{+}$. PD1 and PDL1 antibodies were utilized to co-stain neutrophils for these checkpoint molecules of interest (AbCam). Samples were processed with our lab's Miltenyi Biotec MACSQuant ${ }^{\circledR}$ flow cytometer. FlowJo (version 9.3.2) was utilized to analyze the data.

\section{Protein Expression}

The expression of the protein platelet endothelial cell adhesion molecule-1 (PECAM-1) and zona occludens-1 (ZO-1) levels were compared in homogenized lung samples from WT and $\mathrm{PD} 1^{-/}$pups following $\mathrm{Sh}$ and CS by separating them by polyacrylamide gel electrophoresis, western blot transfer and immunoblot detection as previously outlined in our laboratory $(29,30)$. Images were digitalized using MultiImage Light Cabinet and the band intensity determined.

\section{Enzyme-Linked Immunosorbent Assay}

Using methods we have previously published (31-33), ELISA was utilized to measure cytokine levels of homogenized lung tissue after $24 \mathrm{~h}$ of sepsis. These cytokines include IL-6, IL-10, and TNF- $\alpha$.

\section{Endothelial Cell Analysis}

After $24 \mathrm{~h}$ of sepsis, lungs were harvested and endothelial cells were isolated and cultured. After 3 passages of isolation and culture, endothelial cells were immunofluorescently stained for VE-cadherin, ICAM and ZO-1 as performed previously by the Vascular Research Laboratory, at the Veterans Affairs Medical Center in Providence, RI $(34,35)$.

\section{Human Samples}

Lung samples from preterm infants exposed to intrauterine inflammation and age-matched controls were obtained from the perinatal autopsy files of Women and Infants Hospital (Providence, RI). The study protocols were approved by the Institutional Review Board and informed consent was obtained in compliance with institutional guidelines (IRBNet \# 792344-5). Medical and autopsy records were reviewed for sex, gestational age, weight, placental findings, and cause of death. Infants with congenital, chromosomal, or other anomalies potentially predisposing to pulmonary anomalies were excluded. To study the effects of intrauterine sepsis/inflammation on pulmonary PD/PDL1 expression, infants were divided in 2 groups according to the presence/absence of acute chorioamnionitis (defined as presence of neutrophils within amnion and chorion of extraplacental membranes and chorionic plate) with histopathologic evidence of fetal inflammatory response (i.e., chorionic and/or umbilical acute vasculitis) (Table 1). Formalin-fixed, paraffin-embedded samples were 
TABLE 1 | Infant clinical characteristics and the extent of lung specimen PD1+.

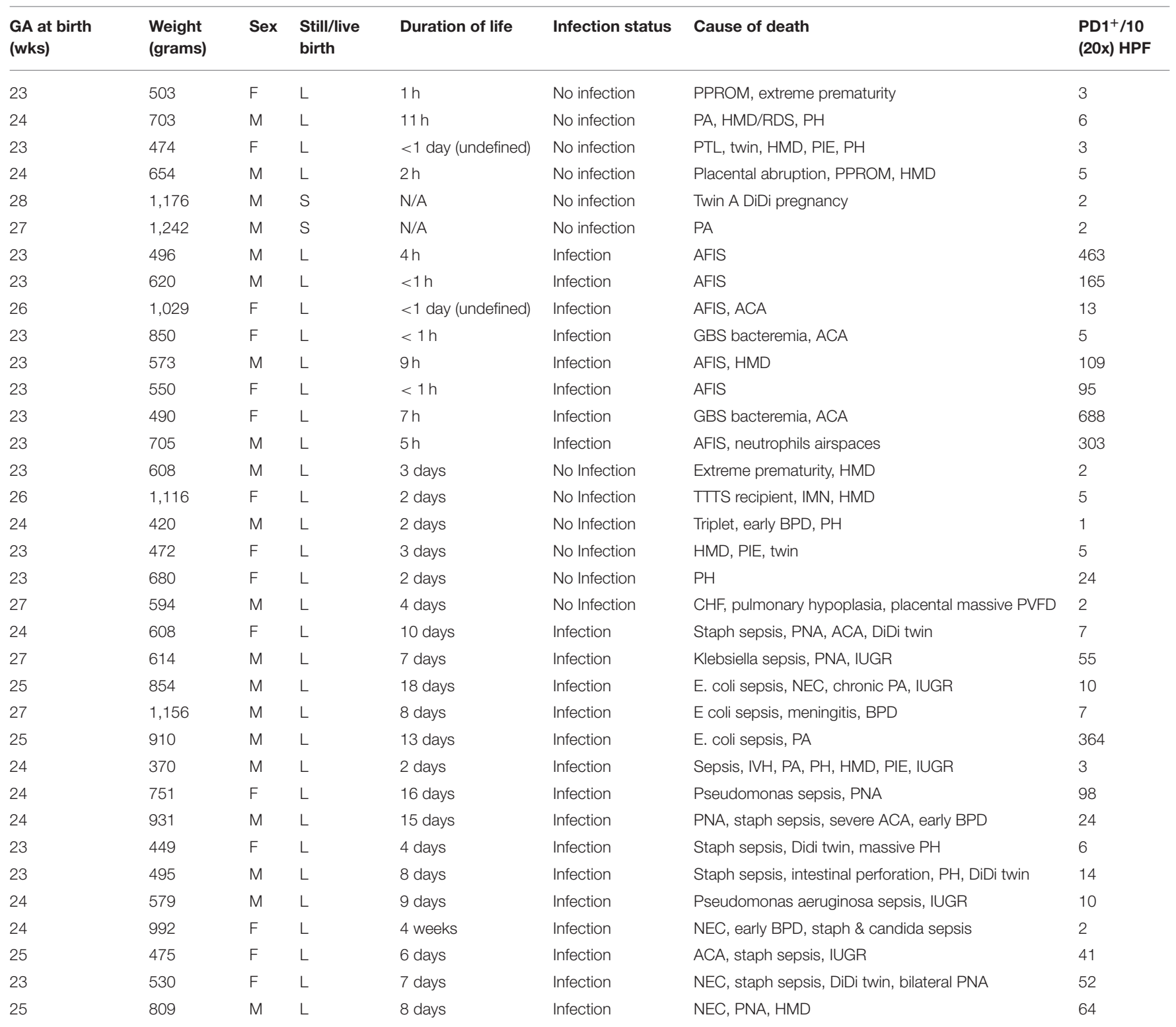

ACA, Acute Chorioamnionitis; AFIS, Amniotic Fluid Infection Syndrome; BPD, Bronchopulmonary Dysplasia; CHF, Congestive Heart Failure; DiDi, Dichorionic Diamniotic; GA, Gestational Age; GBS, Group B Strep; HMD, Hyaline Membrane Disease; HPF, High Power Field; IMN, Ischemic Myocardial Necrosis; IUGR, Intrauterine Growth Retardation; IVH, Intraventricular Hemorrhage; NEC, Necrotizing Enterocolitis; PA, Placental Abruption; PH, Pulmonary Hemorrhage; PIE, Pulmonary Interstitial Emphysema; PNA, Pneumonia; PROM, Preterm Premature Rupture of Membranes; PTL, Premature Labor; PVFD, Perivillous Fibrin Deposition; RDS, Respiratory Distress Syndrome; TाTS, Twin to Twin Transfusion Syndrome.

immunostained for PD1 and PDL1 and analyzed by a boardcertified perinatal pathologist (by MD) with expertise in neonatal pulmonary pathology who was blinded to the clinical data.

Here we specifically stained for PD1 on post-mortem lung tissue of neonates who died either immediately after birth, i.e., within $24 \mathrm{~h}$, or in a delayed manner, i.e., after $48 \mathrm{~h}$ of life. Presence of infection as delineated by diagnosis of chorioamnionitis, bacteremia, pneumonia, NEC, or amniotic fluid infection syndrome (AFIS). Other non-infectious causes of death included myocardial necrosis, pulmonary hemorrhage, placental abruption, and hyaline membrane disease with associated respiratory distress syndrome (HMD/RDS). Finally, in an effort to quantify the cumulative change in the numerical density of $\mathrm{PD} 1$ positive $\left(\mathrm{PD}^{+}\right)$cells among groups the number of $\mathrm{PD}^{+}$cells per 10 high powered fields (HPF), at $20 \times$ magnification, was determined for each lung autopsy specimen.

\section{Statistical Analysis}

Statistical analyses were accomplished with SigmaPlot 12.5 (Systat Software, San Jose, CA). Categorical data was assessed using $\chi^{2}$ or Fisher's exact test. The data were tested for normality 


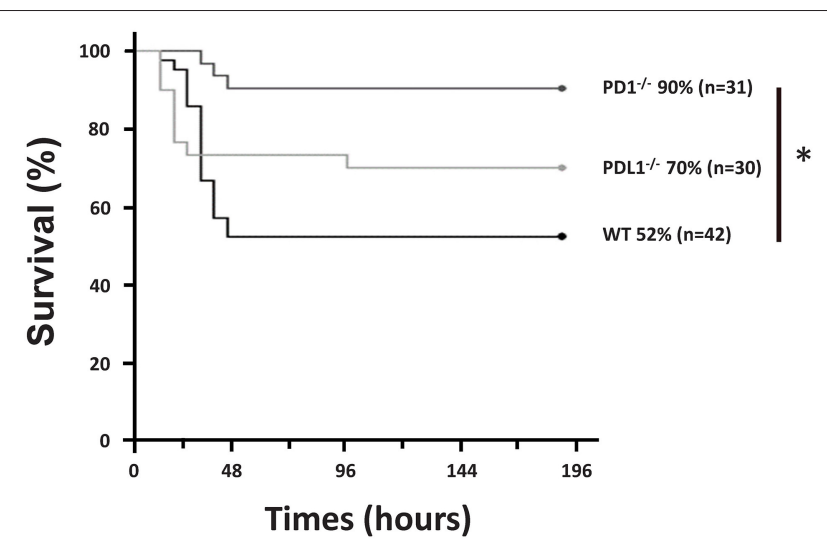

FIGURE 1 | PD1 deficiency improved survival after cecal slurry (CS). C57BL/6 WT and PD1 and PDL1 deficient mice were subjected to CS, and survival was recorded. $\mathrm{PD} 1^{-/-}$mice had a $90 \%$ survival rate compared to WT counterparts who only had $52 \%$ survival over a 7 -day survival study. Those with deletion of PDL1 had a survival of $70 \%$ which was not significantly improved from the WT group. ( ${ }^{*} P<0.05$ vs. WT, log-rank survival analysis; $n=31-42 /$ group).

and normally distributed data sets were analyzed by $T$-test; nonnormally distributed data sets were analyzed by Mann-Whitney $\mathrm{U}$ in order to assess continuous data across 2 groups. Continuous data are expressed as mean and standard error of the mean. Oneway analysis of variance (ANOVA) with Holm-Sidak post-hoc analysis was used for continuous data across multiple groups. Survival analysis was undertaken using Kaplan Meier curves. Alpha was set to 0.05 .

\section{RESULTS}

\section{Survival Study}

In agreement with our recent publication (28), we found that, following CS in WT pups, survival was noted to be $52 \%$ by 7 days $(n=42)$. However, in the $\mathrm{PD}^{-/-}$pups, survival was noted to be markedly improved to $90 \%(p=0.001)$ following septic challenge $(n=31)$. Similarly, survival analysis $(n=30)$ of $\mathrm{PDL}^{-/-}$neonatal mice after CS resulted in $70 \%$ survival. While this, like the $\mathrm{PD}^{-/-}$group, trended toward improved survival over the WT group it was not statistically different (Figure 1). Inasmuch, the remainder of the study focused on the impact of PD1, not PDL1 gene deficiencies impacts here.

\section{Lung Edema}

Among WT pups, lung edema (as measured by Wet:Dry weight ratio/index) was noted to increase after CS compared to Sh $(p<$ 0.05). However, among the $\mathrm{PD} 1^{-/-}$pups, there was no difference in lung edema between Sh and CS groups. In addition, $\mathrm{PD}^{-/-}$ CS pups showed significantly less edema compared to WT CS groups ( $p<0.05$; Figure 2A).

\section{Lung Bacterial Burden}

Interestingly, unlike our previously reported rise in peritoneal bacterial burden (28), there was minimal bacteria detected in the homogenized lung samples across all 4 groups, Sh and CS in both WT vs. $\mathrm{PD}^{-/-}$pups (Figure 2B).

\section{Lung Histology}

No gross architectural changes or diffuse alveolar damage were noted following $\mathrm{CS}$ in either the WT or the $\mathrm{PD}^{-/-}$pups. However, CS did induce mild morphological changes in the lungs of the WT pups. This was most markedly noted in alveolar thickening and mildly increased intra-alveolar hemorrhage. These alterations were not noted in the lungs of $\mathrm{PD}^{-/-}$pups after CS (Figure 3A).

Naphthol esterase staining revealed an increased presence of neutrophils in the lungs after CS among the WT pups. Unlike the WTs, there is no significant change in neutrophil influx between Sh and CS groups among the $\mathrm{PD}^{-/-}$population (Figure 3B).

As a functional assessment, beyond a quantitative determination of neutrophil presence in the lungs, we undertook to evaluate MPO expression in the lung. This is an indirect measure of neutrophilic metabolism. Levels were lowest at $4 \mathrm{~h}$ after septic challenge (or Sh), with an increase at $12 \mathrm{~h}$ and highest levels at $24 \mathrm{~h}$ across all groups (Figure 3C; data for 4 \& $12 \mathrm{~h}$ not shown). Although there was a trend of increase after sepsis in both mice strains, with attenuation among $\mathrm{PD} 1^{-/-}$mice, this finding did not reach statistical significance.

\section{CD18, CD177, and PECAM-1 Expression on Pulmonary Neutrophils}

On flow cytometric analysis, we gated for pulmonary neutrophils

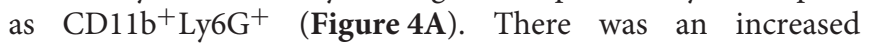
neutrophil count after CS among WT pups, but no difference among the $\mathrm{PD}^{-/-}$pups (Figure 4B).

We next gated for CD18 expression upon these pulmonary

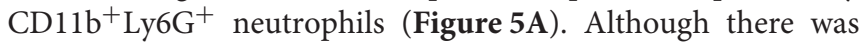
no difference in the percentage of $\mathrm{CD} 11 b^{+} \mathrm{Ly}_{6 \mathrm{G}}{ }^{+} \mathrm{CD} 18^{+}$cells among the groups, there was an increased number of $\mathrm{CD} 18^{+}$ neutrophils in WT mouse lung cells following CS compared to the other three (WT Sh, PD1 ${ }^{-/}-\mathrm{Sh}$, and CS) groups (Figure 5B). However, on analysis of the percentage of $\mathrm{CD}_{1} 8^{+}$cells, there is no difference among the groups (Figure 5C).

We next assessed CD177 expression upon pulmonary neutrophils (Figure 5D). In WT CS pups, fewer pulmonary neutrophils were noted to express CD177 compared to Sh group. However, in $\mathrm{PD}^{-/-} \mathrm{CS}$ pups, the reverse was observed, wherein a considerably greater percentage of pulmonary neutrophils expressed CD177 (Figure 5E). When accounting for cell numbers, this corresponded to an increase in total number of $\mathrm{CD}_{177^{+}}$neutrophils in lungs following CS compared with Sh for both WT and $\mathrm{PD}^{-/-}$pups (Figure 5F).

No difference was noted in PECAM-1 expression across WT or PD1 ${ }^{-/-}$pups following Sham or CS injections (Figures 6A,B). In a previous study, PECAM-1 levels in human neonatal lung tissue were significantly increased following intubation, suggesting endothelial cell proliferation in response to stress of mechanical ventilatory methods (36). 

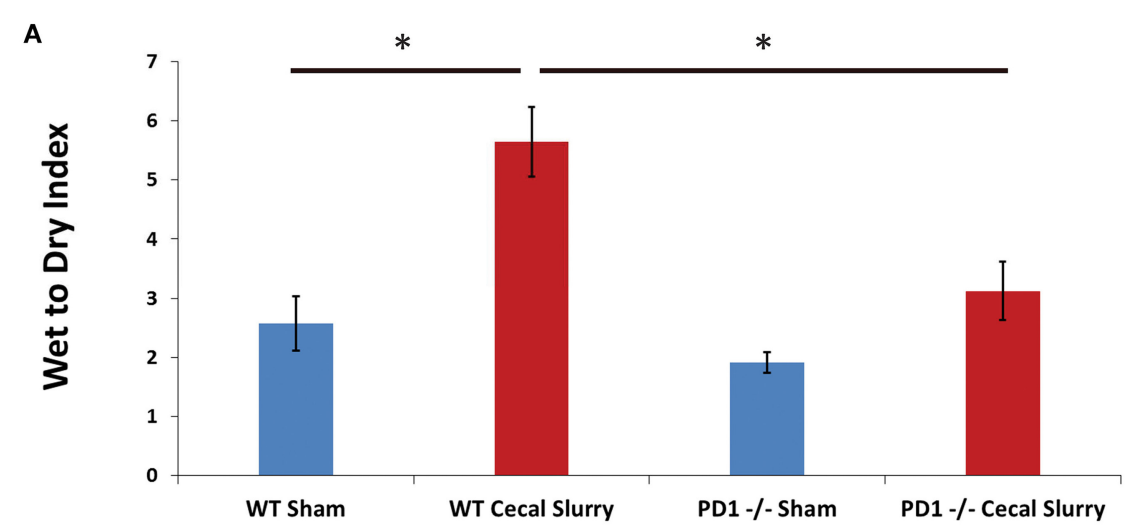

B

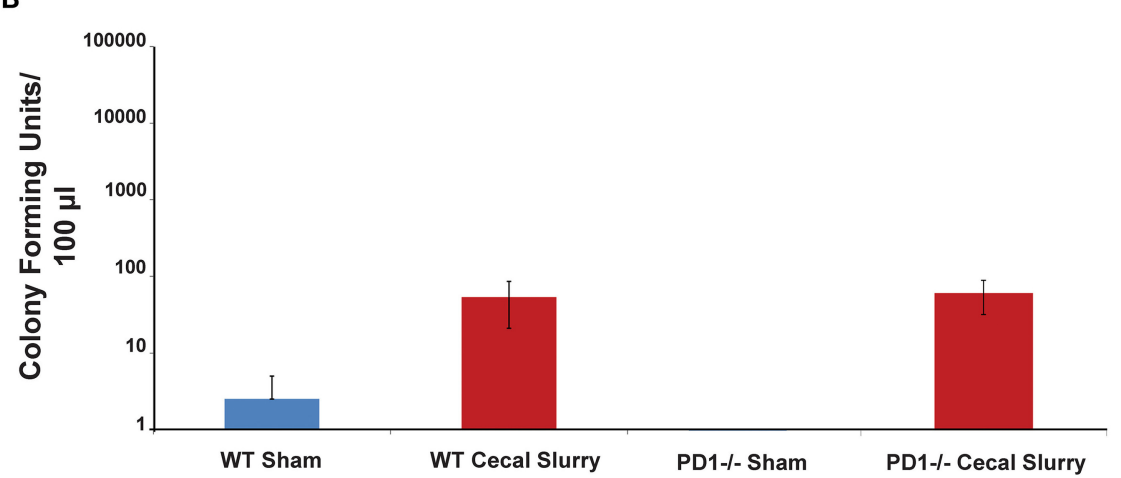

FIGURE 2 | Pulmonary edema as measured by Wet to Dry index of lung weights (A). Lungs of wildtype (WT) mice following cecal slurry (CS) had significantly more edema compared to lungs of the PD1 ${ }^{-/-}$mice after CS. Mean \pm SEM, $n=5-13$ per group. $\left({ }^{*} P<0.05\right.$ vs. WT CS group; $t$-test). Bacterial burden in the peritoneal cavity (B) among wildtype (WT) mice. The sham group $(n=4)$ and the cecal slurry (CS) group $(n=18)$ had no significant difference in Colony Forming Units (CFU) measured after culture of peritoneal lavage. Bacterial burden among PD1 ${ }^{-1-}$ pups after sham $(n=7)$ or CS $(n=18)$. Similar to the WTs, there was no significant difference in peritoneal lavage bacterial CFU counts after sham or CS injections. Mean $\pm S E M ; P>0.05$ (not different) vs. sham group (PD1 $\left.{ }^{-/-} C S\right) ; t$-test.

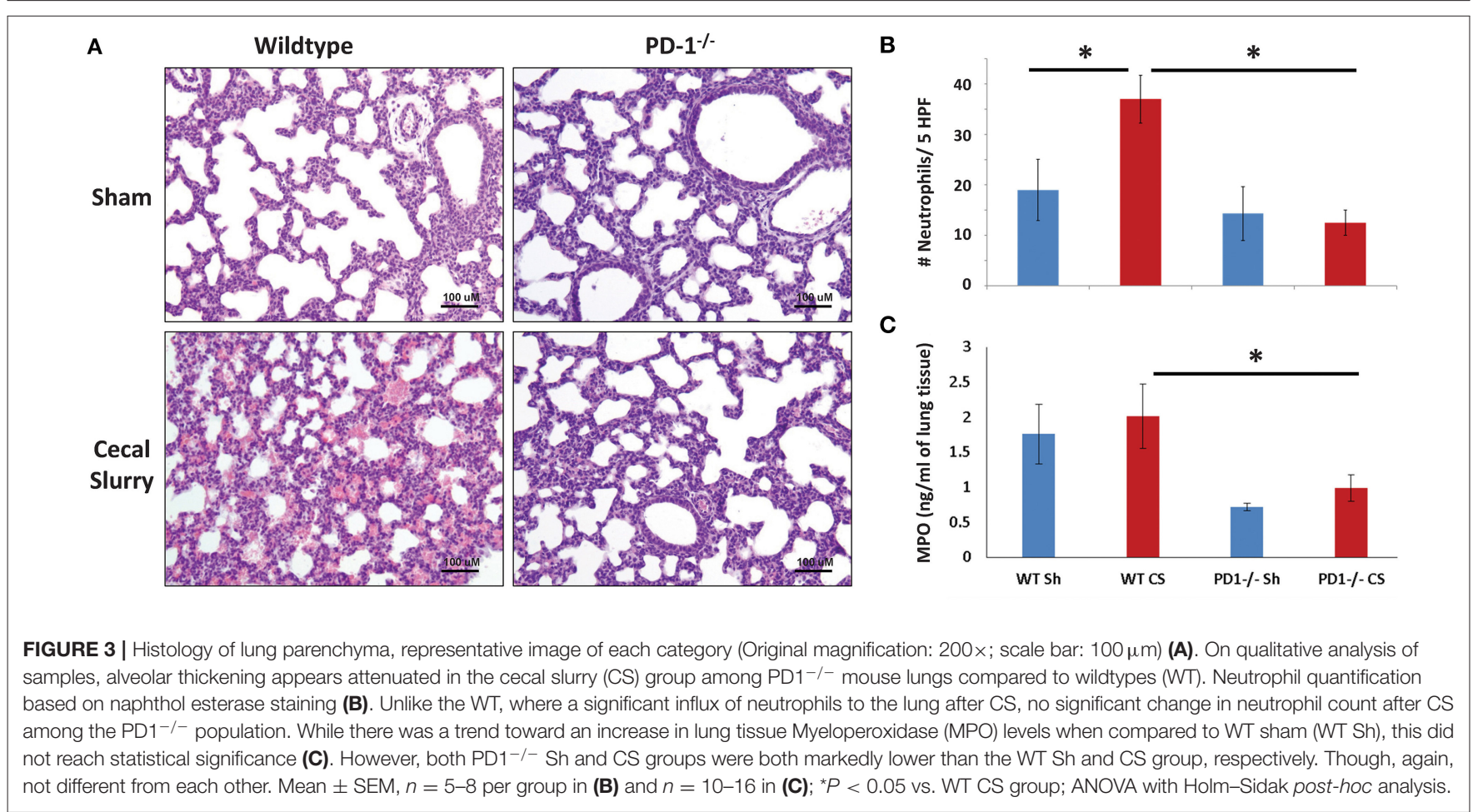


A

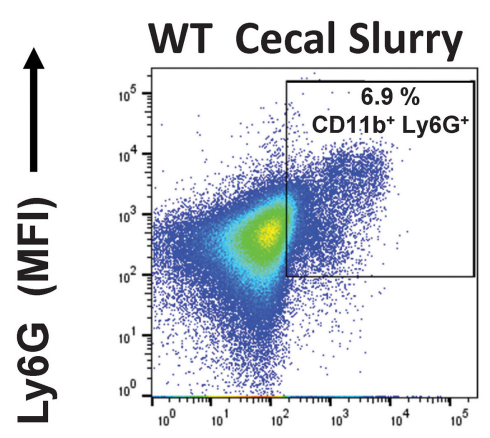

CD11b (MFI)
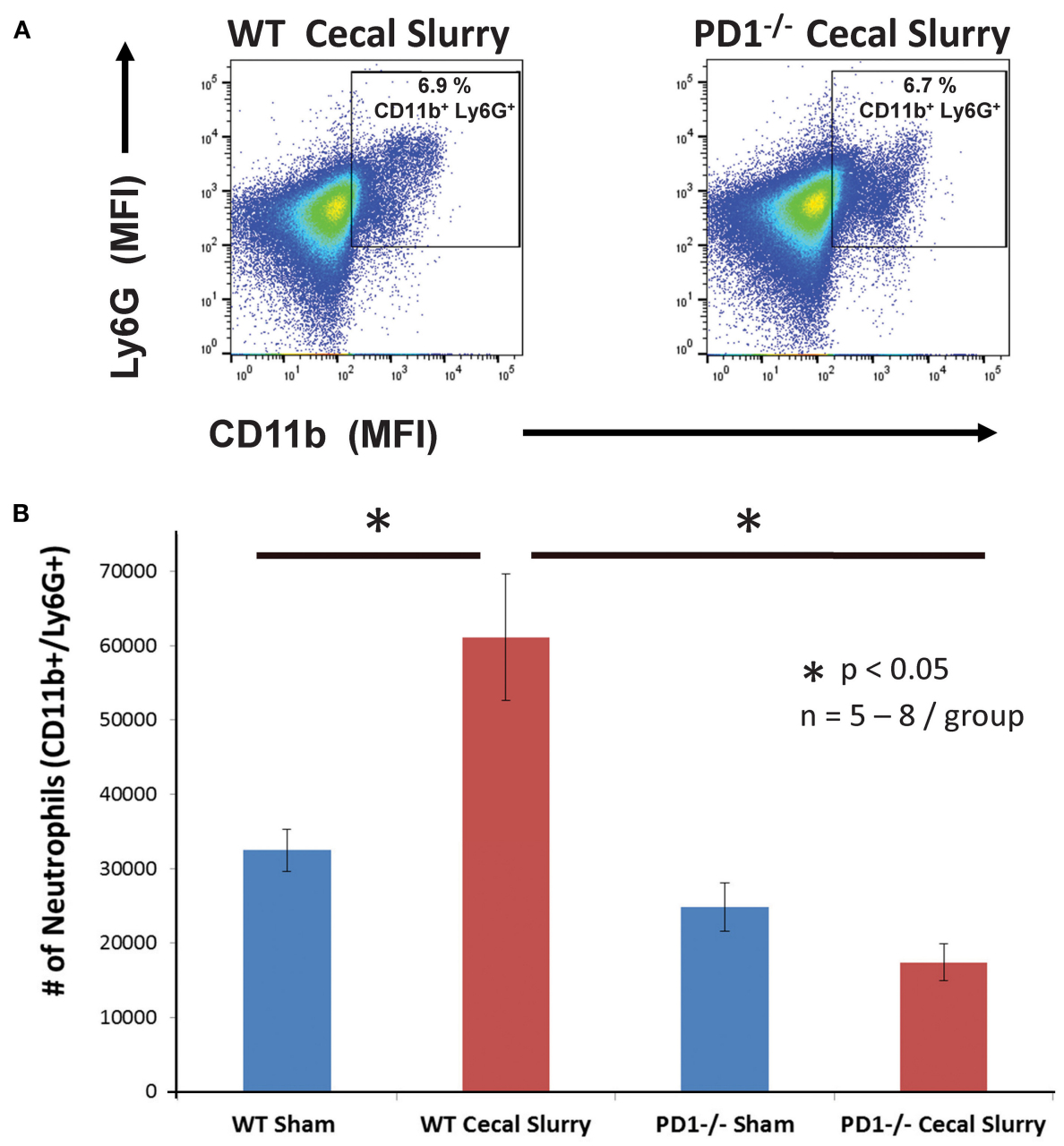

FIGURE 4 | Neutrophils increase in wildtype (WT) but not PD1-/- cecal slurry (CS) mouse lung tissue. (A) Flow cytometry with neutrophils being gated as CD11b and Ly6G-positive among lung samples for WT-CS group vs. PD1-1- CS mouse (paired representative dot-plots). Mean Fluorescence Intensity (MFI). The summary data from repeated experiments indicate a marked rise in the neutrophil number (B) in WT CS lung tissue when compared to Shams. However, this was not changed between PD1-/- Sh and CS animals. Mean \pm SEM, $n=5-8$ per group; ${ }^{*} P<0.05$ vs. WT CS group; ANOVA with Holm-Sidak post-hoc analysis.

\section{Lung Zona Occludens-1 Expression}

ZO-1 expression in the lung, based on homogenized lung tissue $24 \mathrm{~h}$ post-injection, was increased after sepsis in both WT and $\mathrm{PD}^{-/-}$mice, however, this increase was not statistically significant (Figures 7A,B). This was counter to our hypothesis based on prior observations in adult mice subjected to an experimental model of indirect acute lung injury that endothelial cell compromise after sepsis would be mediated by downregulation of ZO-1 $(37,38)$.

\section{Endothelial Cell Culture}

To explore the changes in adhesion molecules in a more detailed fashion, we immunofluorescently stained ZO-1 in isolated and cultured endothelial cells from lungs after $24 \mathrm{~h}$ of Sh or CS injection (Figure 7C). Of note, the distribution of ZO-1 was altered after sepsis, but this change is muted among the $\mathrm{PD}^{-/-}$ murine lungs.

\section{Lung Tissue Cytokine Expression}

We next measured cytokine expression in homogenized lung tissue after $24 \mathrm{~h}$ of Sh or CS mice to test whether the inflammatory micro-environment would be altered in the presence or absence of PD1. Sepsis elevated IL-10 and TNF- $\alpha$ among WT mice, but this effect was lost among $\mathrm{PD}^{-/-}$murine lungs. Although a similar pattern was found for IL-6, this did not reach statistical significance (Figure 8). A limitation of the animal study design is that tissue of survivors (but not those mice who perished) were analyzed; with this being a neonatal model our numbers were limited by how many mice were born within each litter, each litter being analyzed separately (i.e., samples were not batched across multiple litters). For cytokine analysis, due to variance of results, this setup led to an underpowered result.

\section{Human Neonatal Lung Pathology Analysis}

In order to assess the clinical relevance of these observations made in rodents, PD1/PDL1 expression was studied in lung 


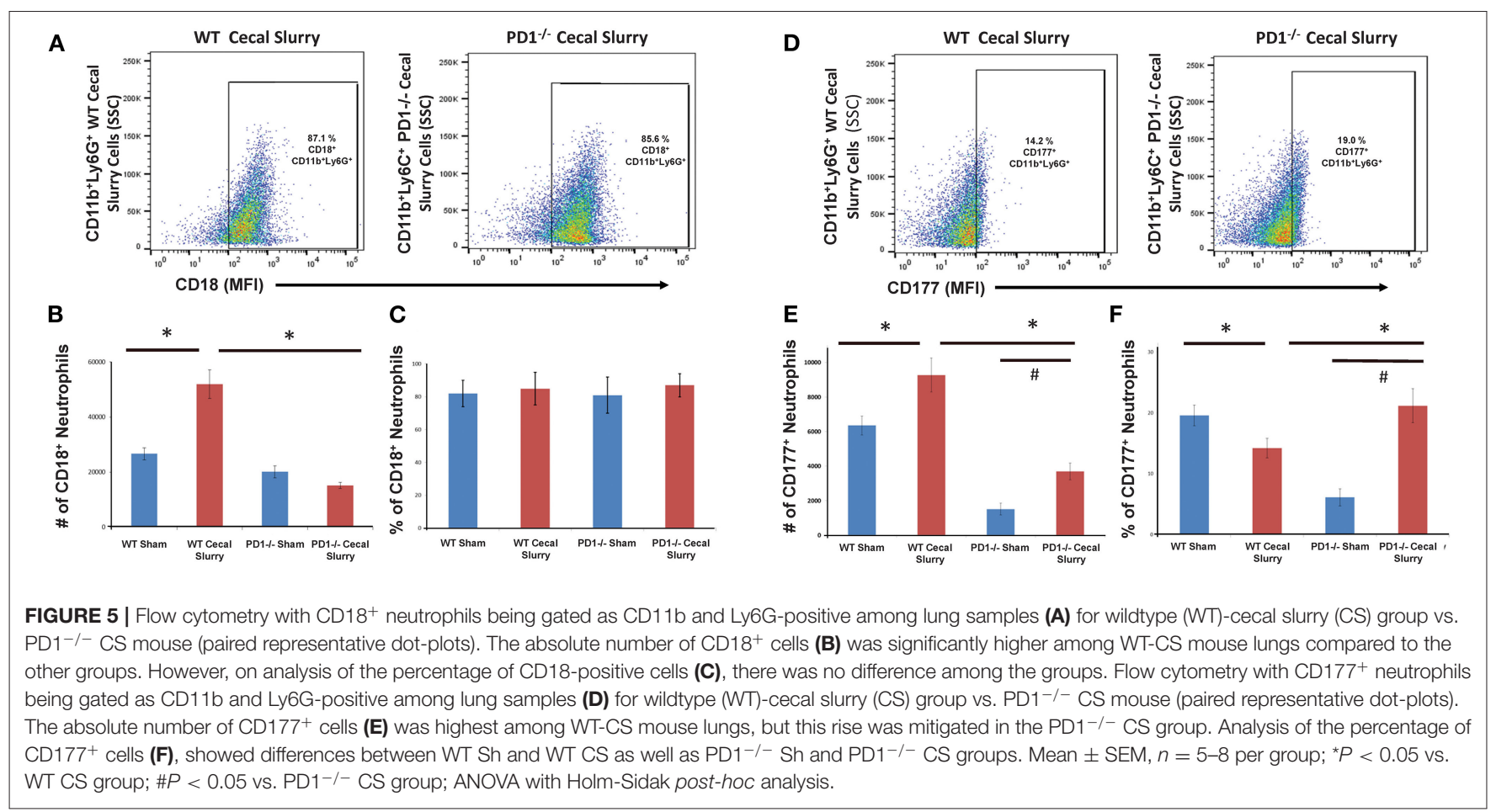

specimens of newborn infants with or without evidence of intrauterine inflammation/sepsis who succumbed within $24 \mathrm{~h}$ of birth. Previous human study on neonatal lungs found that wet weights or edema is associated with pathologically significant inflammation of lung parenchyma (39). Here we found that lungs of infants with evidence of antenatal inflammation/infection $[N$ = 8; "Duration of Life" group $=$ Infection $<24 \mathrm{~h}$ (Table 1)] uniformly displayed abundant PD1-immunoreactive cells, often preferentially located in peribronchial location or in lymphoid aggregates in interstitium and interlobular septa (Figure 9A, "EC1: Amniotic Fluid Infection Syndrome"). In contrast, the lungs of age-matched control infants without evidence of antenatal inflammation/no infection $[N=6$; "Duration of Life" group $=$ No Infection $<24 \mathrm{~h}$ (Table 1$)$ ] were virtually devoid of PD1-immunoreactive cells (Figure 9A, "EC17: Abruption, no inflammation"). The numerical density of PD1-positive cells as summary data is depicted in Figure 9B. In this respect, newborns dying within $24 \mathrm{~h}$ of birth, diagnosed as infected/septic had a pronounced increase in PD1 positive staining (Figure 9B). Further, while reduced in those newborns that survived beyond the first $24 \mathrm{~h}$, a PD1 positive signal was still evident even in the later mortalities if they too were diagnosed with infection/sepsis.

\section{DISCUSSION}

Lung injury in clinical sepsis is a common and often devastating end-organ injury following intra-abdominal polymicrobial insult. The neonatal sepsis model of CS induces gross changes in the lung upon necropsy. To better assess this injury beyond subjective direct visualization, we undertook to quantify

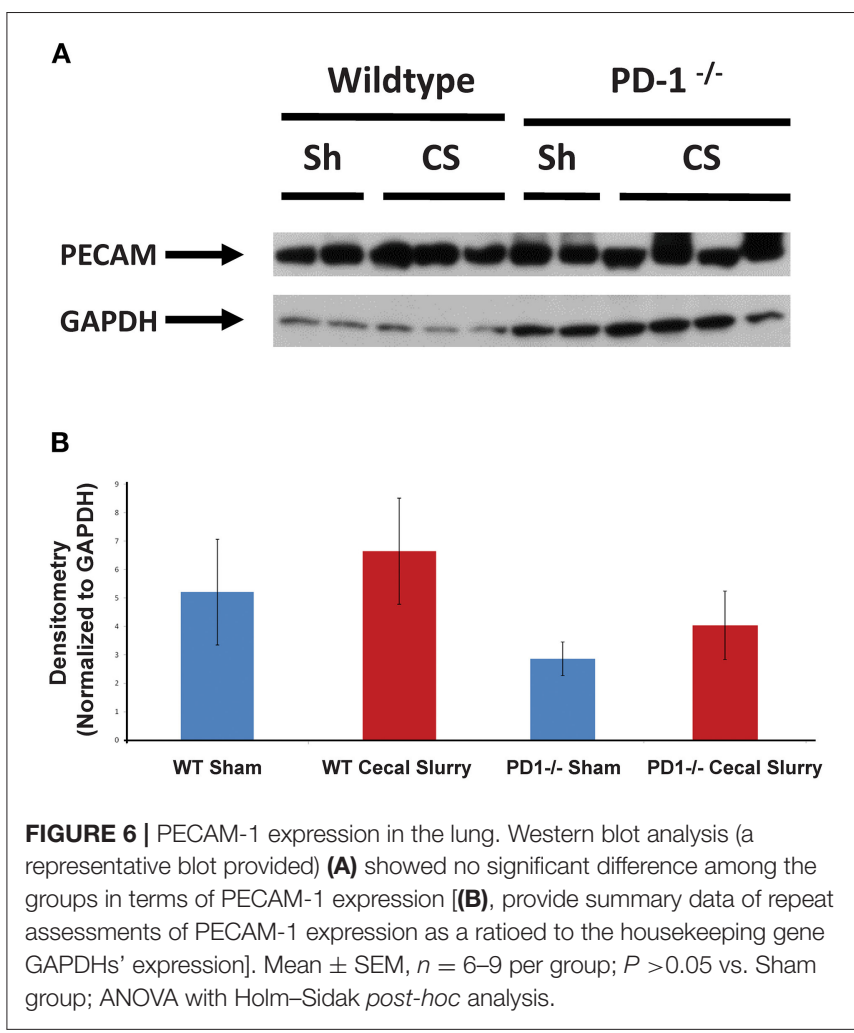

the edema in the lungs as a rudimentary marker of injury. Edema is clearly evidenced in the lungs of septic WT mice, however, among the $\mathrm{PD}^{-/-}$group, the statistically significant 


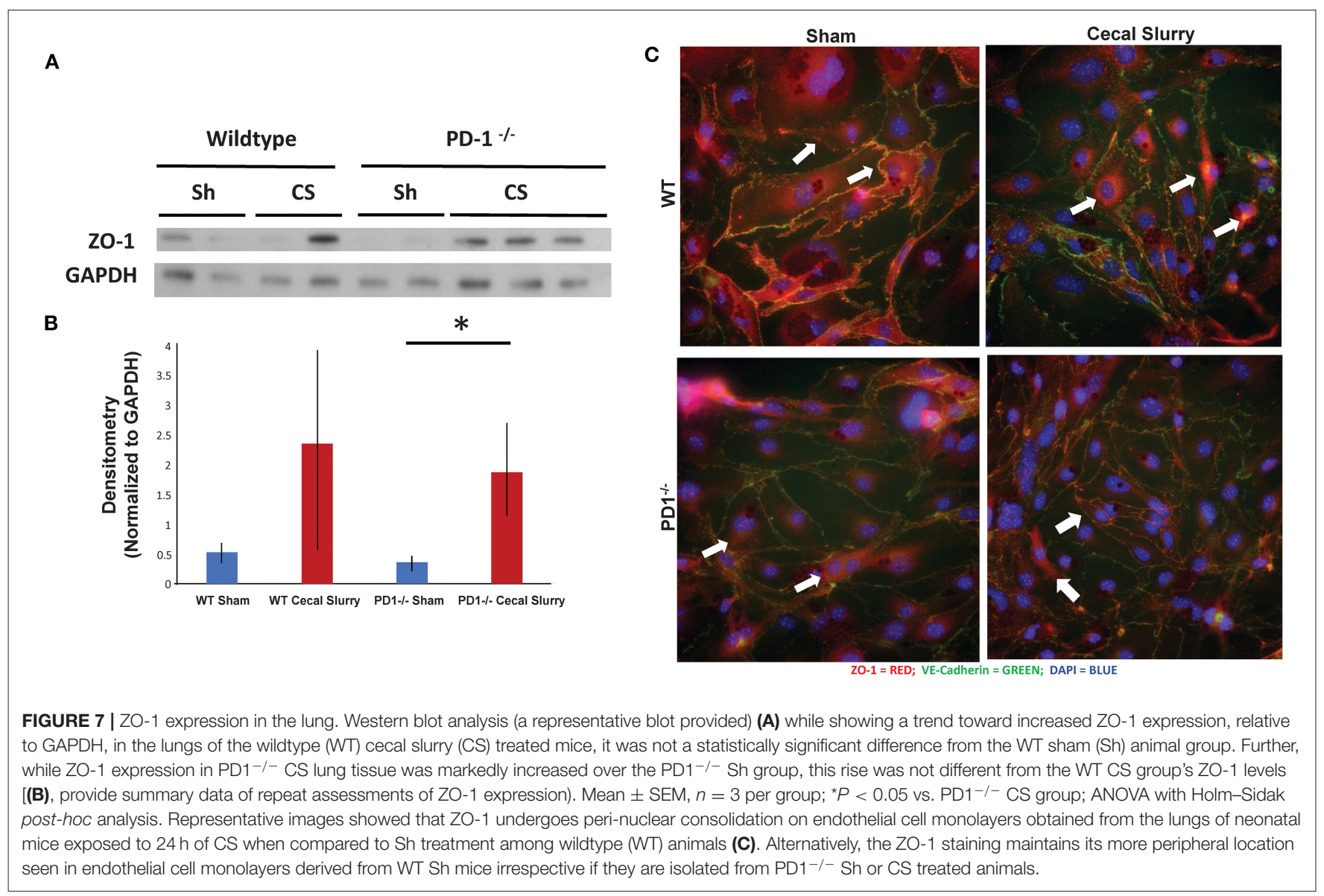

increase that we witnessed in the WT is now lost. This suggests that deletion of the PD1 gene has a protective effect against pulmonary fluid accumulation after remote septic insult.

This supports what we have seen in human septic lung injury. Blood leukocytes of adult septic patients expressed higher levels of PD1 than their non-septic counterparts. Septic patients who survived a component of indirect Acute Lung Injury had lower levels of PD1 expression compared to non-survivors (17). Our question was: do newborns with sepsis also incur changes to the lung that correspond to PD1:PDL1 expression?

Having established a clear role for PD1 in attenuating neonatal lung injury in a septic mouse model, we next endeavored to correlate this with human lung samples and to establish clinical relevancy for the PD1 and PDL1 interaction in the neonatal septic state. With IRB approval, we forged a clinical collaboration that allowed us to analyze autopsy samples of septic and non-septic newborns that had been previously biobanked, and to stain their lung tissue for our checkpoint molecule of interest. We analyzed a total of 20 randomly selected human lung specimens, with non-septic lungs consistently expressing less PD1, and with a less consistent attenuated expression of PDL1. This human data led us to ask: what can experimental sepsis tell us about the underlying mechanism of remote lung injury in neonates?

On histology, the WT mice demonstrated clear lung injury after CS sepsis. In the $\mathrm{PD}^{-/-}$mice compared to WT, however, the alveolar thickening appears mildly attenuated. To characterize the histology further, we quantified the neutrophils present in the lungs by utilizing naphthol esterase immunohistochemistry. We saw that CS is associated with increased neutrophil influx, suggesting that this one-hit model of intra-abdominal sepsis was inducing an indirect effect of increased neutrophil presence in the pulmonary parenchyma. Unlike the WTs, there is no significant change in neutrophil influx after CS among the $\mathrm{PD}^{-/-}$population. This reinforced our supposition that PD1 gene deletion is protective against the lung injury incurred after CS, with neutrophil influx being a marker of this damage.

What mechanisms promote increased cellular congestion in the lung parenchyma? We hypothesized that adhesion molecule(s), like Zona occludens-1 (ZO-1), which promotes inter-cellular integrity $(40,41)$, may be compromised in the setting of sepsis and PD1:PDL1 burden in the lung. However, based on protein expression from western blot analysis of homogenized lung tissue, we found that the pattern of amplified ZO-1 expression after sepsis was comparable in both groups, contrary to our hypothesis. This led us to alternatively hypothesize that the differences in lung permeability might not so much be a result of changes in the level of $\mathrm{ZO}-1$ expression, but might result from differences in the pattern of cellular expression? 
To test this hypothesis, we isolated and ex vivo cultured neonatal lung endothelial cells from various Sh or CS mice and immunofluorescently stained them for adhesion molecule expression pattern. Among the WT, the ZO-1 staining was noted to be consolidate around the nucleus of the cells derived from septic mice, unlike the comparative Sh animals' cells (where it was mostly at the periphery of the cell surface). In the $\mathrm{PD} 1^{-/-}$ mouse cells, however, the peripheral location of the adhesion molecule was maintained, even in the setting of CS. We conclude that perhaps the cytokine milieu of the lungs is affecting the way that ZO-1 localizes in cells, either in addition to direct or indirect neutrophilic interaction discussed earlier. In this regard, we noted that IL-6 expression was increased in both groups, but the increase was much less pronounced among the $\mathrm{PD} 1^{-/-}$mice. The levels of IL-10 exhibited a similar pattern, as did TNF- $\alpha$. This suggests a muted inflammatory environment in the setting of PD1 loss.

CD177 was chosen as a neutrophil marker on our flow cytometry studies. Demaret et al. previously identified CD177 on human adult peripheral blood neutrophils as being markedly upregulated among septic shock patients compared to healthy volunteer controls. Especially with our neonatal population, the implications of CD177 expression not only on chemotaxis but also on cellular maturation may be a potential area for further exploration (42). CD177 associates with CD18 as part of the neutrophils' Mac-1 $\beta 2$ integrin. Bai et al. demonstrated that ligation of CD177 downregulated transmigration across vascular endothelium and thus inhibited cellular localization to the source of injury or sepsis (43). Interestingly, this was independent of PECAM-1 expression, suggesting multiple manners in which neutrophil localization may be regulated (43).

With the neonatal reliance on innate immunity to fight bacterial infections, neutrophils should be particularly scrutinized. Pre-term neonates have been shown to be particularly at risk due to impaired neutrophilic migration compared to neutrophils of full-term neonates (44). Raymond et al. have also suggested that not only is chemotaxis impaired among pre-term neonates, but this corresponds to impaired bacterial clearance secondary to diminished pathogen recognition (45). The Moldawer Lab forged significant progress in the model of intra-abdominal neonatal sepsis, one which was expanded upon here to include study of the effects of presence of or genetic deletion of PD1 (46).

PD1 expression on cells may be a distinctive factor in how organ damage and ultimately survival differs in the setting of sepsis. A limitation of our study is that the human data is strictly correlative; we do not have a confirmed mechanism within human neonates to link PD1 expression with lung injury and death. With this stated, our exploration into PD1 expression in human lung tissues opens doors for further more specific investigations into the pathways through which the sequelae of sepsis unfold. Human pre-term neonatal monocytes have been shown on flow cytometry to express increased PD1 during sepsis (47). This amplified PD1 expression correlated with ante-natal steroid administration in this population. For analysis neonates were divided into early-onset and late-onset. Different from our human analysis, late-onset

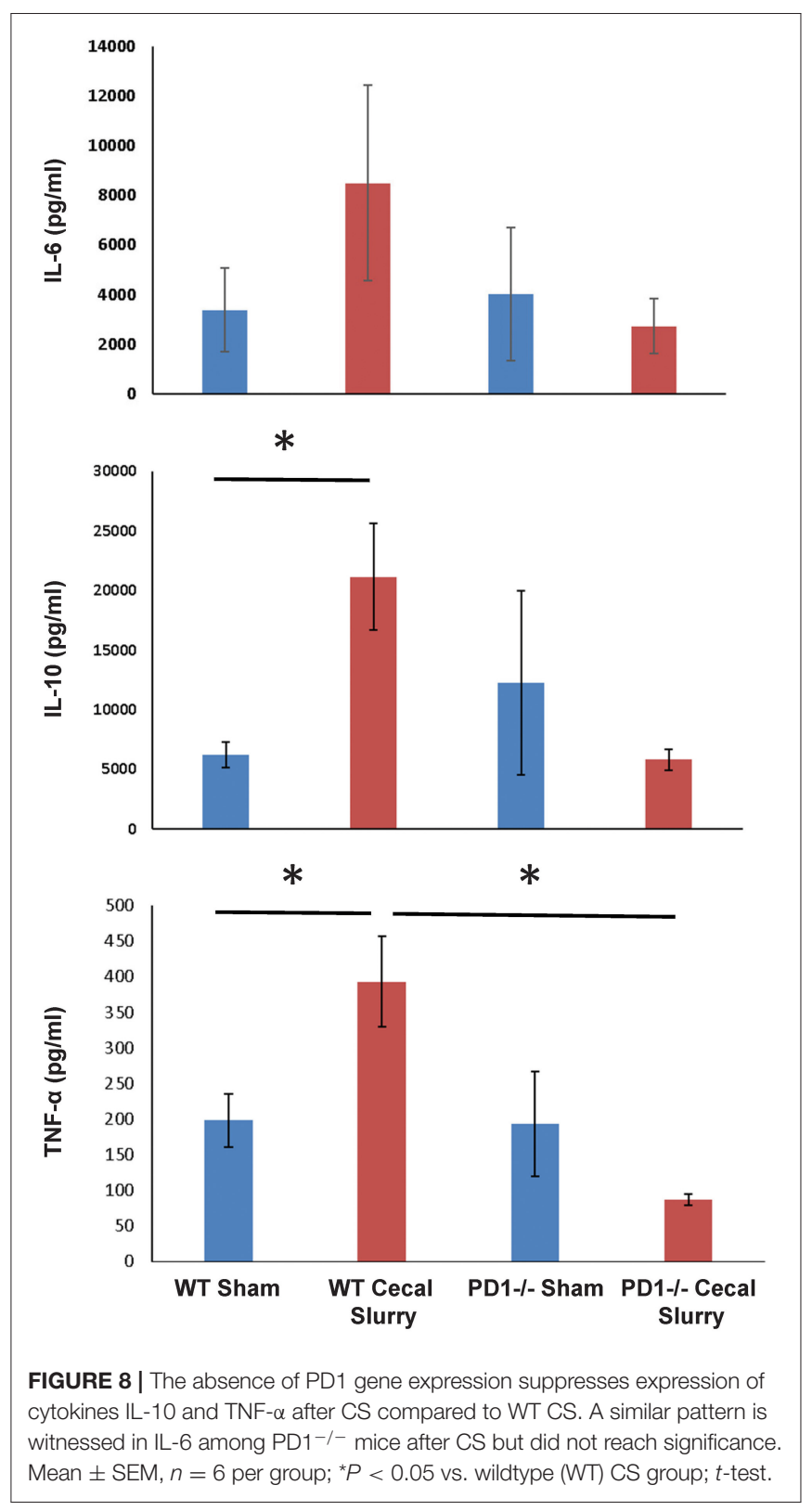

sepsis patient more strongly correlated with PD1 expression compared to early-onset. Further investigation into peripheral vs. pulmonary parenchymal expression of PD1 in infected neonates could provide insight into the immune effects of the associated pathway.

In summary: murine neonatal lungs are sensitive to extrapulmonary sepsis as an isolated insult. This is in contrast to adult mouse lungs, which require cellular priming to incur evidence of lung injury (48). By deleting PD1 gene expression, we attenuate this lung injury, with less edema, fewer neutrophils, and loss of compensatory ligand upregulation. Both PD1 and PDL1 are highly expressed on neutrophils present in the lung after sepsis, suggesting a direct cellular mechanism for increased cellular pulmonary congestion. And finally, epithelial 


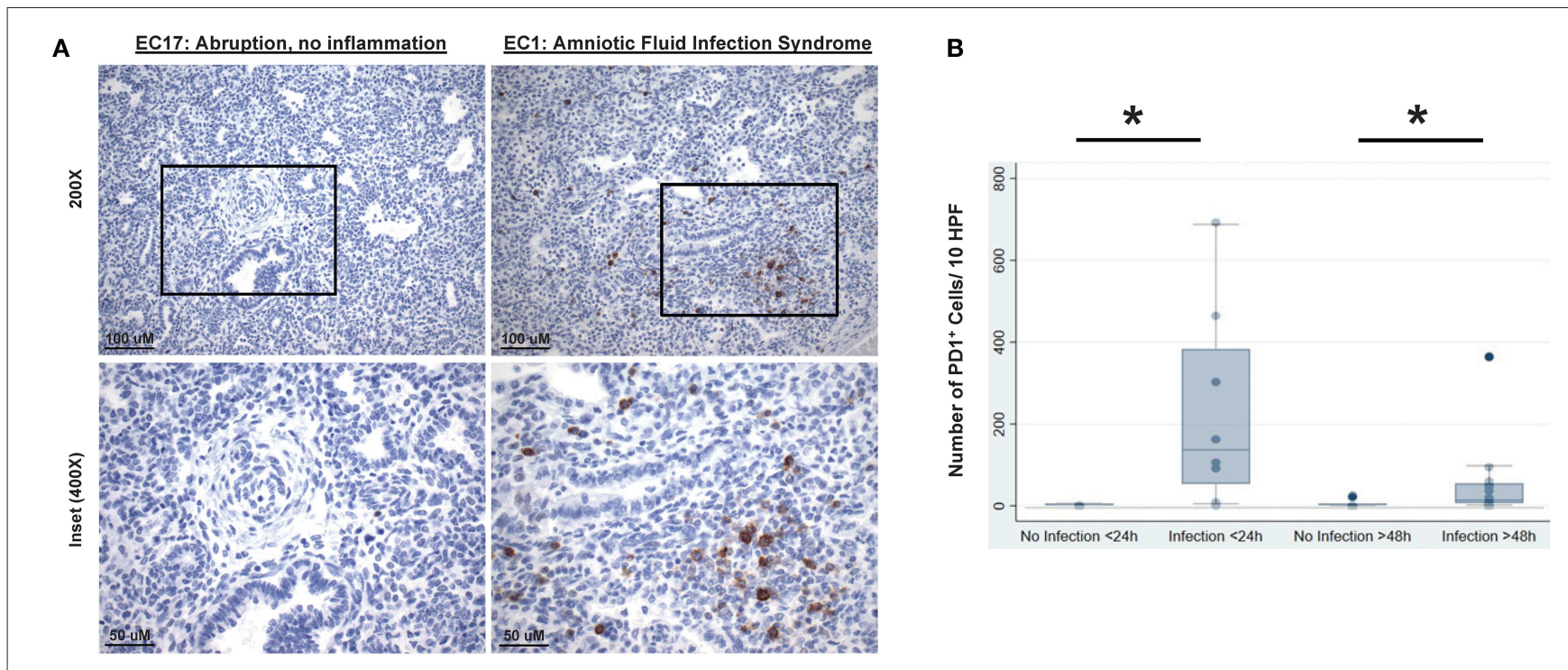

FIGURE 9 | Representative lung autopsy specimens derived of a non-septic (patient EC17: cause of death "abruption, no inflammation") and septic newborn (patient EC1: cause of death "amniotic fluid infection syndrome") who died either immediately after birth, i.e., within 24h, stained for their expression of PD1 (A). Original [top half (A)] image magnification $\times 200$, scale bar: $100 \mu \mathrm{m}$; inset [lower half (A)] at magnification $\times 400$, scale bar: $50 \mu \mathrm{m}$. The cumulative change in the numerical density of PD1 positive cells per 10 high powered fields (HPF) (B), at 20x magnification, is presented for lung autopsy specimens from either non-septic (No Infection) or septic (Infection) newborn whom died either immediately after birth, i.e., within $24 \mathrm{~h}(<24 \mathrm{~h})$, or in a delayed time, i.e., after $48 \mathrm{~h}(>48 \mathrm{~h})$ of life. Data is provided as box and whisker plot; * $P<0.05$, "No Infection $<24 \mathrm{~h}(n=6)$ " vs. "Infection $<24 \mathrm{~h}(n=8)$ " group or "No Infection $>48 \mathrm{~h}(n=7)$ " vs. "Infection $>48 \mathrm{~h}(n=15)$ " group; Kruskal-Wallis test.

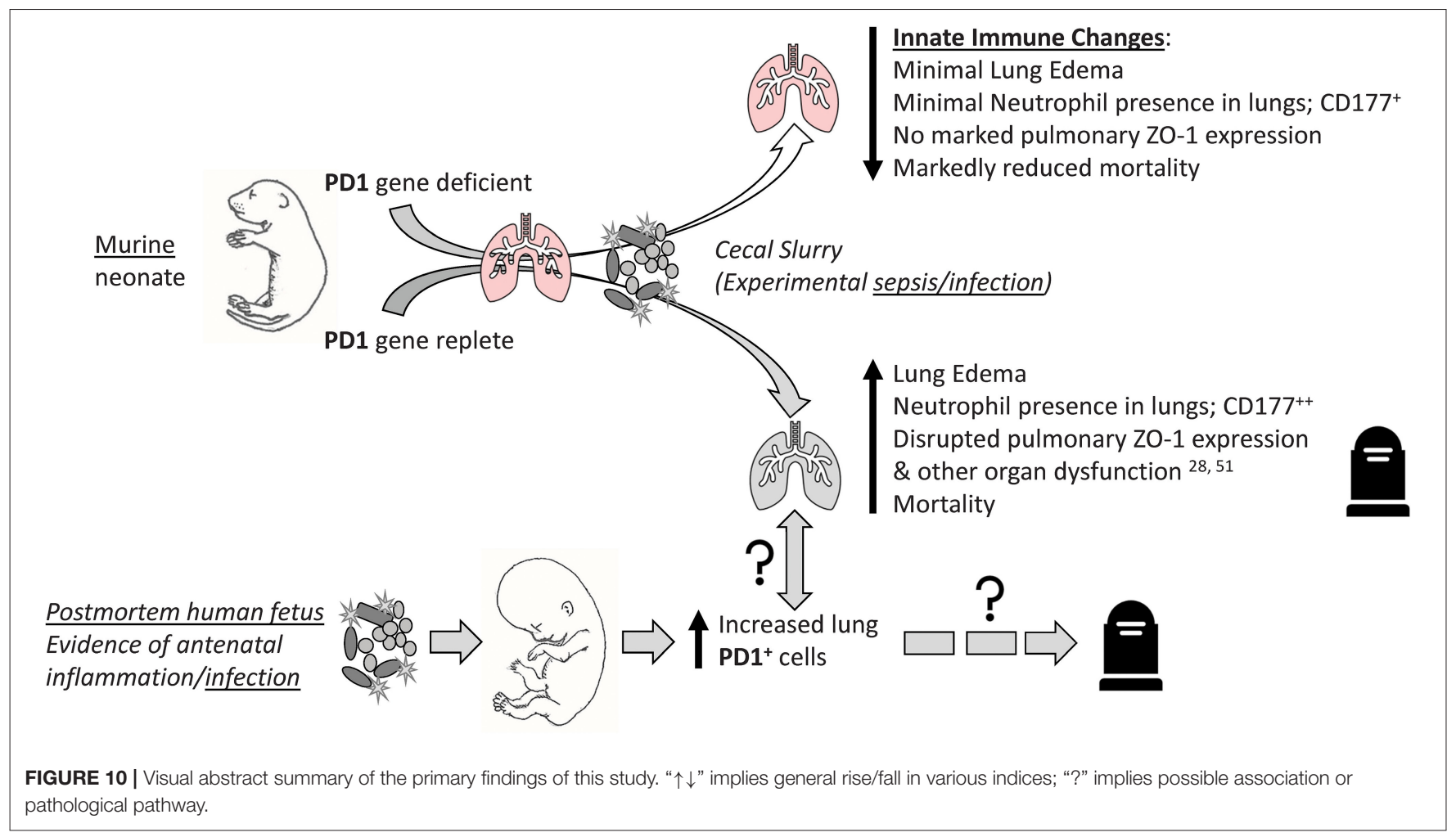

cell adhesive junction interactions and the lung tissue cytokine microenvironment are disrupted after sepsis, but PD1 deletion reduces these factors closer to a non-septic state.
In previous research, patients were at higher risk for contracting nosocomial infections during their protracted recovery from the initial septic insult (49). This risk correlated 
with expression of PD1 within their circulation. When PD1 is ligated via binding to one of its 2 ligands, it acts to prevent the activation of immune cells. This causes downregulation of the function of $\mathrm{T}$ and pro-B cells, among others. It also contributes to inhibition of macrophage function in the setting of sepsis (25). Conversely, when we somehow inhibit the function of PD1 (either by completely deleting the gene responsible for the protein creation; or by partially blocking it via an antagonizing agent), we can observe these effects. The immune paralysis induced by sepsis and mediated by PD1 is now reversed, and the innate immune system is re-activated to clear or neutralize the septic challenge. Given the emerging central role for PD1 in the septic response in the adult population, we undertook to assess the contribution of this checkpoint protein in the neonatal demographic.

Not only within patients afflicted with infections, but also within patients afflicted with cancer, is the understanding of PDl's relationship with the endothelium important. A study by Li et al. described a flubendazole treatment model of mice afflicted with melanoma and found that it depressed PD1 expression on melanoma cells themselves and also diminished PECAM1 expression, thus potentially inhibiting angiogenesis amongst cancer cells (50).

Invariant natural killers $\mathrm{T}$ cells may provide a cellular mechanism that could explain the results found in our study of the PD1:PDL1 interactions and subsequent cascade. In the same model of murine neonatal sepsis, but among $i \mathrm{NKT}^{-/-}$ mice, survival was improved following CS. This may have been mediated by an attenuation in end-organ damage including the liver and the site of infectious nidus, namely the peritoneal cavity (51). In contrast, the Wang lab showed that pre-treatment with an $i$ NKT cell stimulator actually improved survival and signs of lung injury compared to non-treated wildtypes (52). Inasmuch, further investigation into $i \mathrm{NKT}$ cells' role in lung injury will be needed to answer the question of whether $i$ NKT cells are responsible for the injury patterns, and septic attenuation described above.

With COVID-19 now in our midst, consideration for the future of lung injury across age groups, including even neonatal populations is important. Neonates have tested COVID-19 positive, particularly when born to infected mothers (53). At present we do not know the downstream harm that neonatal COVID-19 infection may inflict on the developing lung. However, here we have demonstrated a possible key to inflammatory processes within neonatal sepsis and lung injury that might be leverage in such individuals. With the goal in mind of unlocking the mechanisms of inflammation/immunosuppression mediating lung injury, we

\section{REFERENCES}

1. Desale M, Thinkhamrop J, Lumbiganon P, Qazi S, Anderson J. Ending preventable maternal and newborn deaths due to infection. Best Pract Res Clin Obstet Gynaecol. (2016) 36:116-30. doi: 10.1016/j.bpobgyn.2016.05.008

2. Epstein L, Dantes R, Magill S, Fiore A. Varying estimates of sepsis mortality using death certificates and administrative aim to continue this investigation among further human lung samples and with murine cell-line-specific knock-outs. By learning how lung injury in neonates with sepsis is mediated, perhaps therapies targeting PD1 may be included amongst the keychain of answers.

Taken together, we concluded that the PD1:PDL1 ligation compounds lung injury, in part by either directly or indirectly altering aspects of the pulmonary innate immune response, and worsens survival among experimentally septic neonatal mice (Figure 10). This is echoed in part by septic human neonatal histology demonstrating increased pulmonary PD1 levels after sepsis. Together, these data suggest that aberrant signaling through the PD1:PDL1 pathway may be a viable therapeutic target in the septic neonate.

\section{DATA AVAILABILITY STATEMENT}

The original contributions presented in the study are included in the article/supplementary material, further inquiries can be directed to the corresponding author/s.

\section{ETHICS STATEMENT}

Human lung autopsy samples were utilized from a specimen bank at Women \& Infants Hospital (Providence, RI) of deceased neonates with Institutional Review Board approval (IRBNet \# 792344-5). All mouse experiments were performed in accordance with National Institutes of Health guidelines and approved by the Animal Use Committee of Rhode Island Hospital (AWC\# 5064-18).

\section{AUTHOR CONTRIBUTIONS}

EF, C-SC, DH, and AA: design and concept. EF, MD, $\mathrm{DH}, \mathrm{C}-\mathrm{SC}$, and YC: conduct of experiments. EF, MD, DH, YC, and AA: results analysis and interpretation. EF, C-SC, and AA: manuscript preparation, revisions, and approval. All authors contributed to the article and approved the submitted version.

\section{FUNDING}

This project was supported by NIH grant K08-GM110495 (DH), NIH grant R35-GM118097 (AA), a Surgical Infections Society Foundation-Basic \& Clinical Translational Research Fellowship (EF), and the Armand D. Versaci Research Scholar in Surgical Sciences Fellowship award (EF).

3. Arefian H, Heublein S, Scherag A, Brunkhorst FM, Younis MZ, Moerer O, et al. Hospital-related cost of sepsis: a systematic review. J Infect. (2016) 74:107-17. doi: 10.1016/j.jinf.2016.11.006

4. Farmer D, Tessier JM, Sanders JM, Sawyer RG, Rotstein $\mathrm{OD}$, Dellinger EP, et al. Age and its impact on 
outcomes with intra-abdominal infection. Surg Infect. (2017) 18:77-82. doi: 10.1089/sur.2016.184

5. Balamuth F. Pediatric severe sepsis in U.S. children's hospitals. Pediatr Crit Care Med. (2014) 15:798-805. doi: 10.1097/PCC.0000000000000225

6. Osterman MJ, Kochanek KD, MacDorman MF, Strobino DM, Guyer B. Annual summary of vital statistics: 2012-2013. Pediatrics. (2015) 135:111525. doi: 10.1542/peds.2015-0434

7. Lawn JE, Wilczynska-Ketende K, Cousens SN. Estimating the causes of 4 million neonatal deaths in the year 2000. Int J Epidemiol. (2006) 35:70618. doi: 10.1093/ije/dyl043

8. Wynn JL, Wong HR, Shanley TP, Bizzarro MJ, Saiman L, Polin RA. Time for a neonatal-specific consensus definition for sepsis. Pediatr Crit Care Med. (2014) 15:523-8. doi: 10.1097/PCC.0000000000000157

9. Maddux AB, Douglas IS. Is the developmentally immature immune response in paediatric sepsis a recapitulation of immune tolerance? Immunology. (2015) 145:1-10. doi: 10.1111/imm.12454

10. Hutchins NA, Unsinger J, Hotchkiss RS, Ayala A. The new normal: immunomodulatory agents against sepsis immune suppression. Trends $\mathrm{Mol}$ Med. (2014) 20:224-33. doi: 10.1016/j.molmed.2014.01.002

11. Buras JA, Holzmann B, Sitkovsky M. Animal models of sepsis: setting the stage. Nat Rev Drug Discov. (2005) 4:854-65. doi: 10.1038/nrd1854

12. Bakowitz M, Bruns B, McCunn M. Acute lung injury and the acute respiratory distress syndrome in the injured patient. Scand J Trauma Resusc Emerge Med. (2012) 20:54. doi: 10.1186/1757-7241-20-54

13. Tang L, Bai J, Chung CS, Lomas-Neira J, Chen Y, Huang X, et al. Active players in resolution of shock/sepsis induced indirect lung injury: immunomodulatory effects of Tregs and PD-1. J Leukoc Biol. (2014) 96:80920. doi: 10.1189/jlb.4MA1213-647RR

14. Lomas-Neira J, Venet F, Chung CS, Thakkar R, Heffernan D, Ayala A. Neutrophil-endothelial interactions mediate angiopoietin2-associated pulmonary endothelial cell dysfunction in indirect acute lung injury in mice. Am J Respir Cell Mol Biol. (2014) 50:193-200. doi: 10.1165/rcmb.2013-0148OC

15. Gill SE, Taneja R, Rohan M, Wang L, Mehta S. Pulmonary microvascular albumin leak is associated with endothelial cell death in murine sepsis-induced lung injury in vivo. PLoS ONE. (2014) 9:e88501. doi: 10.1371/journal.pone.0088501

16. Monaghan SF, Thakkar RK, Heffernan DS, Huang X, Chung CS, LomasNeira J, et al. Mechanisms of indirect acute lung injury: a novel role for the coinhibitory receptor, programmed death-1. Ann Surg. (2012) 255:15864. doi: 10.1097/SLA.0b013e31823433ca

17. Monaghan SF, Thakkar RK, Tran ML, Huang X, Cioffi WG, Ayala A, et al. Programmed death 1 expression as a marker for immune and physiological dysfunction in the critically ill surgical patient. Shock. (2012) 38:11722. doi: 10.1097/SHK.0b013e31825de6a3

18. Lomas-Neira J, Chung CS, Perl M, Gregory S, Biffl W, Ayala A. Role of alveolar macrophage and migrating neutrophils in hemorrhage-induced priming for ALI subsequent to septic challenge. Am J Physiol Lung Cell Mol Physiol. (2006) 290:L51-8. doi: 10.1152/ajplung.00028.2005

19. Li W, Zhu S, Zhang Y, Li J, Sama AE, Wang P, et al. Use of animal model of sepsis to evaluate novel herbal therapies. $J$ Vis Exp. (2012):3926. doi: 10.3791/3926

20. Lu P, Sodhi CP, Jia H, Shaffiey S, Good M, Branca MF, et al. Animal models of gastrointestinal and liver diseases. Animal models of necrotizing enterocolitis: pathophysiology, translational relevance, and challenges. Am J Physiol Gastrointest Liver Physiol. (2014) 306:G917-28. doi: 10.1152/ajpgi.00422.2013

21. Lin PW, Stoll BJ. Necrotising enterocolitis. Lancet. (2006) 368:127183. doi: 10.1016/S0140-6736(06)69525-1

22. Kazarian KK, Perdue PW, Lynch W, Dziki A, Nevola J, Lee CH, et al. Porcine peritoneal sepsis: modeling for clinical relevance. Shock. (1994) 1:20112. doi: 10.1097/00024382-199403000-00008

23. Wynn JL, Scumpia PO, Delano MJ, O’Malley KA, Ungaro R, Abouhamze A, et al. Increased mortality and altered immunity in neonatal sepsis produced by generalized peritonitis. Shock. (2007) 28:675-83. doi: 10.1097/SHK.0b013e3180556d09

24. Ishida Y, Agata Y, Shibahara K, Honjo T. Induced expression of PD-1, a novel member of the immunoglobulin gene superfamily, upon programmed cell death. EMBO J. (1992) 11:3887-95. doi: 10.1002/j.1460-2075.1992.tb05481.x
25. Thibult ML, Mamessier E, Gertner-Dardenne J, Pastor S, Just-Landi S, Xerri L, et al. PD-1 is a novel regulator of human B-cell activation. Int Immunol. (2013) 25:129-37. doi: 10.1093/intimm/dxs098

26. Monaghan SF, Chung CS, Chen Y, Lomas-Neira J, Fairbrother WG, Heffernan DS, et al. Soluble programmed cell death receptor-1 (sPD-1): a potential biomarker with anti-inflammatory properties in human and experimental acute respiratory distress syndrome (ARDS). J Transl Med. (2016) 14:312. doi: 10.1186/s12967-016-1071-x

27. Huang X, Venet F, Wang YL, Lepape A, Yuan Z, Chen Y, et al. PD-1 expression by macrophages plays a pathologic role in altering microbial clearance and the innate inflammatory response to sepsis. Proc Natl Acad Sci USA. (2009) 106:6303-8. doi: 10.1073/pnas.0809422106

28. Young WA, Fallon EA, Heffernan DS, Efron PA, Cioffi WG, Ayala A. Improved survival after induction of sepsis by cecal slurry in PD-1 knockout murine neonates. Surgery. (2016) 36:240-. doi: 10.1016/j.surg.2016.11.008

29. Wu Y, Chung CS, Chen Y, Monaghan SF, Patel S, Huang X, et al. A novel role for programmed cell death receptor ligand-1 (PDL1) in sepsis-induced intestinal dysfunction. Mol Med. (2017) 22:830-40. doi: 10.2119/molmed.2016.00150

30. Chung CS, Venet F, Chen Y, Jones LN, Wilson DC, Ayala CA, et al. Deficiency of Bid protein reduces sepsis-induced apoptosis and inflammation, while improving septic survival. Shock. (2010) 34:15061. doi: 10.1097/SHK.0b013e3181cf70fb

31. Perl M, Chung CS, Perl U, Biffl WL, Cioffi WG, Ayala A. Beneficial versus detrimental effects of neutrophils are determined by the nature of the insult. J Am Coll Surg. (2007) 204:840-52; discussion 85243. doi: 10.1016/j.jamcollsurg.2007.02.023

32. Song GY, Chung CS, Jarrar D, Cioffi WG, Ayala A. Mechanism of immune dysfunction in sepsis: inducible nitric oxide-meditated alterations in p38 MAPK activation. J Trauma. (2002) 53:276-82; discussion 28273. doi: 10.1097/00005373-200208000-00015

33. Biron BM, Chung CS, O'Brien XM, Chen Y, Reichner JS, Ayala A. Cl-Amidine prevents histone 3 citrullination and neutrophil extracellular trap formation, and improves survival in a murine sepsis model. J Innate Immun. (2017) 9:22-32. doi: 10.1159/000448808

34. Ventetuolo CE, Aliotta JM, Braza J, Chichger H, Dooner M, McGuirl, et al. Culture of pulmonary artery endothelial cells from pulmonary artery catheter balloon tips: considerations for use in pulmonary vascular disease. Eur Respir J. (2020) 55:1901313. doi: 10.1183/13993003.01313-2019

35. Harrington EO, Newton J, Morin N, Rounds S. Barrier dysfunction and RhoA activation are blunted by homocysteine and adenosine in pulmonary endothelium. Am J Physiol Lung Cell Mol Physiol. (2004) 287:L10917. doi: 10.1152/ajplung.00421.2003

36. De Paepe ME, Mao Q, Powell J, Rubin SE, DeKoninck P, Appel N, et al. Growth of pulmonary microvasculature in ventilated preterm infants. Am J Respir Crit Care Med. (2006) 173:204-11. doi: 10.1164/rccm.200506-927OC

37. Xu S, Yang Q, Bai J, Tao T, Tang L, Chen Y, et al. Blockade of endothelial, but not epithelial, cell expression of PD-L1 following severe shock attenuates the development of indirect acute lung injury in mice. Am J Physiol Lung Cell Mol Physiol. (2020) 318:L801-12. doi: 10.1152/ajplung.00108.2019

38. Lomas-Neira J, Monaghan SF, Huang X, Fallon EA, Chung CS, Ayala A. Novel role for PD-1:PD-L1 as mediator of pulmonary vascular endothelial cell functions in pathogenesis of indirect ARDS in mice. Front Immunol. (2018) 9:3030. doi: $10.3389 /$ fimmu.2018.03030

39. De Paepe ME, Shapiro S, Hansen K, Gündogan F. Postmortem lung volume/body weight standards for term and preterm infants. Pediatr Pulmonol. (2014) 49:60-6. doi: 10.1002/ppul.22818

40. Stevenson BR, Siliciano JD, Mooseker MS, Goodenough DA. Identification of ZO-1: a high molecular weight polypeptide associated with the tight junction (zonula occludens) in a variety of epithelia. J Cell Biol. (1986) 103:755-66. doi: 10.1083/jcb.103.3.755

41. Hwang I, An BS, Yang H, Kang HS, Jung EM, Jeung EB. Tissue-specific expression of occludin, zona occludens- 1 , and junction adhesion molecule A in the duodenum, ileum, colon, kidney, liver, lung, brain, and skeletal muscle of C57BL mice. J Physiol Pharmacol. (2013) 64:11-18.

42. Demaret J, Venet F, Plassais J, Cazalis MA, Vallin H, Friggeri A, et al. Identification of $\mathrm{CD} 177$ as the most dysregulated parameter in a microarray study of purified neutrophils from septic shock 
patients. Immunol Lett. (2016) 178:122-30. doi: 10.1016/j.imlet.2016. 08.011

43. Bai M, Grieshaber-Bouyer R, Wang J, Schmider AB, Wilson ZS, Zeng L, et al. CD177 modulates human neutrophil migration through activationmediated integrin and chemoreceptor regulation. Blood. (2017) 130:2092100. doi: 10.1182/blood-2017-03-768507

44. Raymond SL, Hawkins RB, Murphy TJ, Rincon JC, Stortz JA, López MC, Ungaro R, et al. Impact of toll-like receptor 4 stimulation on human neonatal neutrophil spontaneous migration, transcriptomics, and cytokine production. J Mol Med. (2018) 96:673-84. doi: 10.1007/s00109-018-1646-5

45. Raymond SL, Mathias BJ, Murphy TJ, Rincon JC, López MC, Ungaro R, et al. Neutrophil chemotaxis and transcriptomics in term and preterm neonates. Transl Res. (2017) 190:4-15. doi: 10.1016/j.trsl.2017.08.003

46. Gentile LF, Nacionales DC, Lopez MC, Vanzant E, Cuenca A, Szpila BE, et al. Host responses to sepsis vary in different low-lethality murine models. PLoS ONE. (2014) 9:e94404. doi: 10.1371/journal.pone.0094404

47. Zasada M, Lenart M, Rutkowska-Zapała M, Stec M, Durlak W, Grudzień A, et al. Analysis of PD-1 expression in the monocyte subsets from non-septic and septic preterm neonates. PLoS ONE. (2017) 12:e0186819. doi: 10.1371/journal.pone.0186819

48. Ayala A, Chung CS, Lomas JL, Song GY, Doughty LA, Gregory SH, et al. Shock-induced neutrophil mediated priming for acute lung injury in mice: divergent effects of TLR-4 and TLR-4/FasL deficiency. Am J Pathol. (2002) 161:2283-94. doi: 10.1016/S0002-9440(10)64504-X

49. Guignant C, Lepape A, Huang X, Kherouf H, Denis L, Poitevin F, et al. Programmed death-1 levels correlate with increased mortality, nosocomial infection and immune dysfunctions in septic shock patients. Crit Care. (2011) 15:R99. doi: 10.1186/cc10112
50. Li Y, Acharya G, Elahy M, Xin H, Khachigian LM. The anthelmintic flubendazole blocks human melanoma growth and metastasis and suppresses programmed cell death protein-1 and myeloid-derived suppressor cell accumulation. Cancer Lett. (2019) 459:268-76. doi: 10.1016/j.canlet.2019.05.026

51. Fallon EA, Chun TT, Young WA, Gray C, Ayala A, Heffernan DS. Program cell death receptor-1-mediated invariant natural killer $t$-cell control of peritoneal macrophage modulates survival in neonatal sepsis. Front Immunol. (2017) 8:1469. doi: 10.3389/fimmu.2017.01469

52. Bolognese AC, Yang WL, Hansen LW, Sharma A, Nicastro JM, Coppa GF, et al. Activation of invariant natural killer $\mathrm{T}$ cells redirects the inflammatory response in neonatal sepsis. Front Immunol. (2018) 9:833. doi: 10.3389/fimmu.2018.00833

53. Shalish W, Lakshminrusimha S, Manzoni P, Keszler M, Sant'Anna GM. COVID-19 and Neonatal respiratory care: current evidence and practical approach. Am J Perinatol. (2020) 37:780-91. doi: 10.1055/s-0040-1710522

Conflict of Interest: The authors declare that the research was conducted in the absence of any commercial or financial relationships that could be construed as a potential conflict of interest.

Copyright (c) 2021 Fallon, Chung, Heffernan, Chen, De Paepe and Ayala. This is an open-access article distributed under the terms of the Creative Commons Attribution License (CC BY). The use, distribution or reproduction in other forums is permitted, provided the original author(s) and the copyright owner(s) are credited and that the original publication in this journal is cited, in accordance with accepted academic practice. No use, distribution or reproduction is permitted which does not comply with these terms. 